\title{
Silver-Catalyzed Intermolecular Bromotrifluoromethoxylation of Alkenes
}

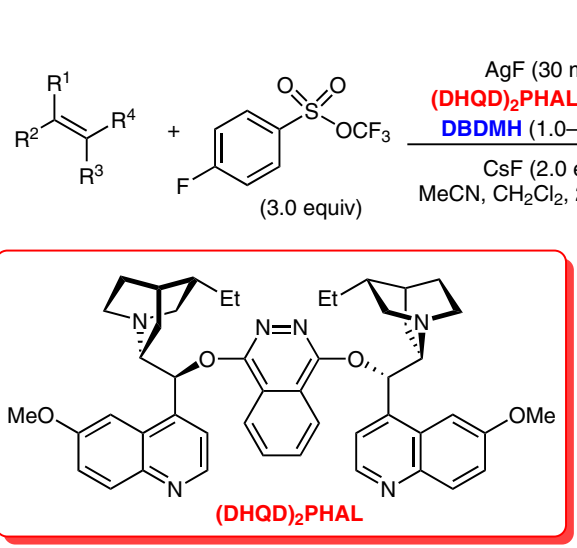

\section{Selected examples:}<smiles>Fc1ccc(C(=C[AsH2][AsH3-])CBr)cc1</smiles>

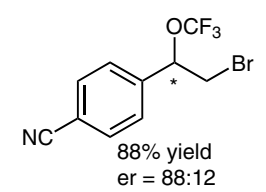<smiles>O=C(OCc1ccccc1)c1ccc([N+](=O)[O-])cc1</smiles>

$\mathrm{OCF}_{3}$<smiles>CC(=Cc1ccccc1)C(C)Br</smiles><smiles>CCCCC(CBr)C(C)CBr</smiles><smiles>[B]C1CCCC1[18OH]</smiles><smiles>[R16]OC1=C(Br)CCCC1</smiles><smiles>COC(CBr)c1ccc(C)cc1C(=O)O</smiles>

$87 \%$ yield $\mathrm{dr}>20: 1$ er $=58.5: 41.5$

$$
\begin{aligned}
& 52 \% \text { yield } \\
& \mathrm{rr}=4.3: 1 \\
& \mathrm{er}=55: 45
\end{aligned}
$$<smiles>CCC12OC(=O)C[C@]1(C)[C@@H]1CC[C@@H](OC(F)(F)F)[C@@H](Br)[C@H]1O2</smiles>

$72 \%$ yield $\mathrm{rr}=4.6: 1$ $\mathrm{dr}>20: 1$

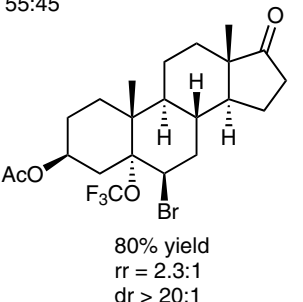

Possible transition-state model:

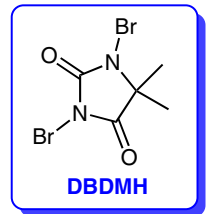

\section{Category}

Metal-Catalyzed Asymmetric

Synthesis and

Stereoselective

Reactions

\section{Key words}

silver catalysis

bromotrifluoromethoxylation

alkenes

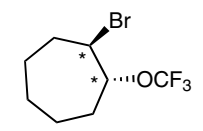

$90 \%$ yield $\mathrm{dr}>20: 1$

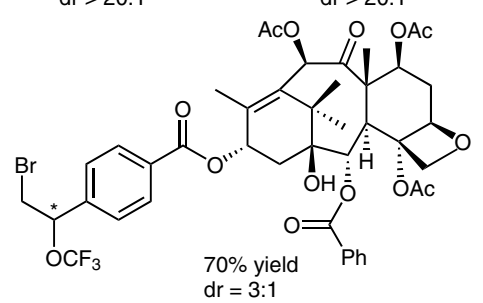

Significance: The development of new methods to introduce a trifluoromethoxy group into drugs or agrochemicals is important because of the strongly electron-withdrawing nature and high lipophilicity of this moiety. The authors report a silver-catalyzed enantioselective bromotrifluoromethoxylation of alkenes with a new trifluoromethoxylation reagent.

SYNFACTS Contributors: Hisashi Yamamoto, Takahiro Sawano Synfacts 2017, 13(08), $0821 \quad$ Published online: 18.07.2017 Dol: 10.1055/s-0036-1590650; Reg-No.: H08417SF
Comment: The developed trifluoromethoxylation reagent, trifluoromethyl 4-fluorobenzenesulfonate, is easily prepared and thermally stable, and shows good reactivity. The bromotrifluoromethoxylation method can be applied to a variety of alkenes, including small, complex molecules. 